\title{
Characteristics of catechin extracted from cocoa husks using microwave assisted extraction (MAE)
}

\author{
PREMY PUSPITAWATI RAHAYU ${ }^{\natural}$, DJALAL ROSYIDI ${ }^{\text {}}$, PURWADI, IMAM THOHARI \\ Department of Animal Product Technology, Faculty of Animal Science, Universitas Brawijaya. Jl. Veteran, Malang 65145, East Java, Indonesia. \\ Tel.: +62-341-553513, Fax.: +62-341-584727, •email: premypuspita@ub.ac.id, ••email: djalal_tht@ub.ac.id
}

Manuscript received: 4 October 2019. Revision accepted: 20 November 2019.

\begin{abstract}
Rahayu PP, Rosyidi D, Purwadi, Thohari I. 2019. Characteristics of catechin extracted from cocoa husks using microwaveassisted extraction (MAE). Biodiversitas 20: 3626-3631. Cocoa husks, a by-product of cocoa processing, were investigated as a source of catechin. The objective of this research was to investigate the best extraction time for catechin of cocoa husk using microwaveassisted extraction (MAE). Four different treatments (4, 6, 8, and $10 \mathrm{~min}$ ) were tested. Catechin was analyzed using Fourier transform infrared (FTIR) spectroscopy, and total phenol content (TPC) and total catechin content (TCC) were determined by liquid chromatography-mass spectrometry (LC-MS). The longest extraction time $(10 \mathrm{~min})$ produced the highest phenolic content, although it was similar to that obtained at $8 \mathrm{~min}$. The IR spectra of the cocoa husk extract were stable for the 4, 6, and 8 min extractions. However, the spectra after the $10 \mathrm{~min}$ extraction showed more peaks, especially for phenolic compounds and catechins. The mass spectra of catechin showed a peak at RT 3.11 and a protonated ion peak $[\mathrm{M}+\mathrm{H}]^{+}$at $\mathrm{m} / \mathrm{z} 307$. The results for TPC, TCC, FTIR, and LC-MS indicated that a 10 min extraction using MAE was the optimum treatment.
\end{abstract}

Keywords: Catechin, cocoa husk extract, extraction time, IR spectra, polyphenol

\section{INTRODUCTION}

The total production of cocoa in East Java in 2016 was 31262 tons/year (Statistic Indonesia, 2018), produced in an area of $34734 \mathrm{Ha}$, with the highest production in the Blitar region. However, cocoa husk waste makes up approximately $74 \%$ of this figure, accounting for about 23134 tons/year. A small amount of the husk is used as animal feed, but the vast majority is left to pollute the environment. It can become infested with pests and diseases, as well as produce air pollution in the form of known greenhouse gases, including methane $\left(\mathrm{CH}_{4}\right)$, carbon dioxide $\left(\mathrm{CO}_{2}\right)$, and nitrous oxide $\left(\mathrm{N}_{2} \mathrm{O}\right)$. Cocoa husks have become a significant environmental problem with increased processing of cocoa beans and the resulting increased waste volume. Consequently, scientists are urgently exploring alternative uses for this large amount of by-products (Bonvehi and Escola Jorda 1998; Redgwell et al. 2003). One potential use is as a source of catechins, which is the focus of this article.

The bioactive compounds of cocoa husks were methylxanthines (theobromine ranged from $1.63 \%$ to $4.77 \%$ and caffeine ranged from $0.04 \%$ to $0.29 \%$ ) and catechins 1.02-6.16 mg/g (Hernández-Hernández et al., 2018). Catechins are classified as monomer flavan-3-ols. These flavonoids are the main biologically active compounds in green tea, which has catechin levels of 60 to $80 \%$ of total flavonoids. The catechin compound group consists of epicatechin (EC), epigallocatechin (EGC), epicatechin gallate (ECG), epigallocatechin gallate (EGCG), catechin, gallocatechin, catechin gallate, and gallocatechin gallate. EGCG is the primary catechin in cocoa and accounts for $48-55 \%$ of the total polyphenols (Velayutham et al. 2008). The phenolic hydroxyl group of catechins can inhibit lipid peroxidation and fat hydrolysis, while the galloyl group contributes to prostacyclin production and the reduced expression of vascular cell adhesion molecule-1 (Velayutham et al. 2008). As antioxidants, catechins can inhibit the oxidation of cholesterol and low-density lipoprotein and suppress platelet aggregation (Kim et al. 2014). Therefore, catechin is often used as a supplement to create functional and healthy foods.

The aim of the present research was to determine optimal duration for extraction of catechin from cocoa husks and to analyze the characteristics of the extracted catechin. This study used microwave-assisted extraction (MAE) because this method requires only a minimal amount of solvent, so the extraction is more effective and efficient (Jain et al. 2009) compare with the brewing (Astill et al., 2001) and maceration (Aswanida, 2015). The MAE may induce electromagnetic waves that disrupt the plant material and enhance the temperature, thus enhance the solubility of target compound in solvent (Delazar et al. 2012).

Catechins can be identified by qualitative analysis using liquid chromatography-mass spectrometry (LC-MS) and Fourier transform infrared (FTIR) spectroscopy. LCMS provides physical separation of compounds for identification of specific compounds in the extract The presence of bioactive catechin compounds in the extract were confirmed by comparing the detected molecular weights ( $\mathrm{m} / \mathrm{z}$ values) with those of a catechin standard and with the previous literature. LCMS has been widely used in 
the characterization of flavan-3-ols, flavonoids, quinic esters of caffeine, thearubigins, and alkaloids from different teas (Del Rio et al. 2004; Clifford et al. 2007; Beretta et al. 2008). Conversely, FTIR is used to identify functional groups in an extract. Catechins contain important functional groups that absorb in the region of $500-1900 \mathrm{~cm}^{1}$. The number of these groups may change in some compounds for a variety of reasons, including the temperature and duration of the extraction (Chen et al. 2006; Senthilkumar et al. 2017). The results from this study can be used to maximize catechin production and reduce waste from cocoa production, with potential financial benefits for farmers.

\section{MATERIALS AND METHODS}

\section{Chemicals and reagents}

Cocoa husks were obtained from the Kampung Cokelat area of Blitar, East Java, Indonesia. The husks were grated, dried, and ground to produce a powder with a particle size of $177 \mu \mathrm{m}$. All chemicals and materials for catechin extraction and analysis were of analytical grade (Merck, Germany) and included catechin standard, 96\% ethanol, propanol, Whatman No. 4 filter paper, Folin-Ciocalteu reagent, saturated sodium carbonate, gallic acid, EGCG standard, potassium bromide $(\mathrm{KBr})$ powder, and an analytical C18 BEH HPLC column $(100 \mathrm{~mm} \times 2.1 \mathrm{~mm}$ inner diameter; $1.7 \mathrm{~lm}$, Waters, Milford, MA, USA).

\section{Catechin extraction and recovery}

The catechin was extracted using the MAE method (Rahayu et al., 2015) (Sharp Model R - 222Y(S)) at level power high $\left(70^{\circ} \mathrm{C}\right)$ with a slight modification. Cocoa husk powder was dissolved in pure ethanol at a ratio of $3 \mathrm{~g}$ powder to $100 \mathrm{~mL}$ ethanol. It soaked for 24 hours. The solution was extracted in microwave oven for 4 (A), 6 (B), 8 (C), or 10 (D) min (one minute on and two minutes off) to avoid overheating. The crude extract was filtered through Whatman no. 4 filter paper, the ethanol was evaporated using rotary evaporator at $55 \mathrm{~mm} \mathrm{Hg}$ pressure and $50^{\circ} \mathrm{C}$. The evaporated extracts were added 2-propanol. The mixture was filtered using Whatman filter paper No 4 and the filtrate was concentrated using a rotary evaporator (IKA RV 10) to remove the solvent. The concentrated filtrate was then analyzed as described below.

\section{Measurements of phenolic content}

Total phenolic content (TPC) was determined using the Folin-Ciocalteu reagent method, as described by Maung and Chamba (2012). Saturated sodium carbonate was prepared and stored for $24 \mathrm{~h}$. Standard concentrations of gallic acid at 25, 50,100, 150, and 200 ppm were freshly prepared at room temperature for each analysis. A solution of $0.5 \mathrm{~mL}$ of $1: 10$ diluted gallic acid in $4.5 \mathrm{~mL}$ of distilled water, $0.2 \mathrm{~mL}$ of Folin reagent (Merck), and $0.5 \mathrm{~mL}$ of saturated sodium carbonate were prepared and used to generate a standard sample analysis curve. A T-1900 UV spectrophotometer was used to determine the absorbance of each sample at $725 \mathrm{~nm}$. The TPC was calculated from absorption values and a linear regression equation to compare the results with the gallic acid standard. The results were shown as ppm gallic acid equivalents (GAE) per gram dry weight of sample $(\mathrm{mg} / \mathrm{g})$.

\section{Preparation of samples for LC-MS/MS analysis}

Fresh stock solutions of catechins were prepared fresh daily at concentrations of $5.10^{-3} \mathrm{~mol} / \mathrm{L}$. Adequate volumes of stock solution were then mixed with catechins at a concentration of $5.10^{-4} \mathrm{~mol} / \mathrm{L}$. The mixed solution was injected with the column equilibrated with the initial mobile phase (Spacil et al. 2010).

\section{LC-MS/MS analysis and measurement of TCC}

The electrospray ionization (ESI) was operated in the positive ion detection mode using the following parameters: desolvation temperature $400{ }^{\circ} \mathrm{C}$, extractor voltage $2 \mathrm{~V}$, capillary voltage $3.2 \mathrm{~V}$, RF lens (hexapole), voltage $1.5 \mathrm{~V}$, nebulization gas flow rate $400 \mathrm{~L} / \mathrm{h}$, cone gas flow rate $150 \mathrm{~L} / \mathrm{h}$, and cone voltage $20 \mathrm{~V}$. The data were analyzed by MassLynx Software version 4.1. The analytical C18 BEH column $(100 \mathrm{~mm} \times 2.1 \mathrm{~mm}$ inner diameter; $1.7 \mu \mathrm{m}$, Waters, Milford, MA, USA) was kept at $35^{\circ} \mathrm{C}$ during chromatographic separation and volume was $1.5 \mu \mathrm{L}$. The samples and $0.05 \%$ acetic acid eluent were stored at $4^{\circ} \mathrm{C}$ (Spacil et al. 2010).

TCC of treatments was quantified using integration of the peaks, with reference to calibrations made using external standards. Calibration curves were constructed for (+)-catechin at concentrations ranging from 0 to $1 \mathrm{mg}$ $\mathrm{mL}-1(\mathrm{r} \geq 0.990)$.

\section{FTIR analysis}

Chemical structure was determined using method as described by Moela et al. (2009) with slight modification. The UV-Vis spectrum was on a GBS UV/VIS 920. One milligram of cocoa husk extraction dried using vacuum desiccator, after that, it was ground and mixed thoroughly with $200 \mathrm{mg}$ of oven-dried $\mathrm{KBr}$ powder of analytical reagent (Merck, DAC, USP). The powder was put in a die and compressed into a transparent disk.

\section{Data analysis}

The data for total phenolic content and catechins were analyzed by analysis of variance using MS Excel software (CORREL statistical function) and the Smallest Significant Difference Test (BNT). The FTIR and LCMS data were compared to data published in the literature.

\section{RESULTS AND DISCUSSION}

\section{Total Phenolic Content (TPC)}

The TPC of the cocoa husk extracts ranged from 6.71$8.65 \mathrm{mg} / \mathrm{mL}$ (Table 1) and varied depending on the extraction duration $(\mathrm{P}<0.05)$. This reflects the increase in the cell wall permeability of the material with increasing extraction change, which increases the solubility and diffusion of phenolic compounds. However, the bioactive compounds of cocoa husk extracts can be damaged if the 
wrong temperature is used for extraction, so the temperature and duration of the extraction need to be considered. Hijazi et al. (2013) reported that the method and extraction time can affect the recovery of total phenolics. Azmir et al. (2013) explained that many factors affect the extraction process, including the temperature, extraction time, solvent, and matrix properties of the material used (leaves, stems, husks, fruit, etc.). In the present study, increasing the extraction time for cocoa husks increased the recovery of TPC (Table 1). The cocoa husk extraction produced TPC amounts for the $4 \mathrm{~min}, 6$ $\mathrm{min}, 8 \mathrm{~min}$, and $10 \mathrm{~min}$ treatments of $6.71 \mathrm{mg} / \mathrm{mL}, 7.18$ $\mathrm{mg} / \mathrm{mL}, 8.35 \mathrm{mg} / \mathrm{mL}$, and $8.65 \mathrm{mg} / \mathrm{mL}$, respectively. The extraction treatment using the maceration method combined with MAE for 10 min produced the largest TPC recovery at $8.65 \mathrm{mg} / \mathrm{mL}$. Based on these results, $10 \mathrm{~min}$ was considered the optimal time for extraction.

Determining the TPC recovery is important for investigating bioactive compounds in cocoa husks at different extraction durations. Previous studies have conducted cocoa husk extraction with the MAE method and different solvents with the aim of obtaining the best yield of bioactive compounds (Hernández-Jiménez et al. 2012; Biesaga et al. 2013; Rahayu et al. 2015). HernándezJiménez et al. (2012) reported that ethanol is the best solvent for extraction of cocoa husk. In the present study, the TPC of cocoa husk extract ranged from $6.71-8.65 \mathrm{mg}$ GAE/mL, whereas Bruna et al. (2009) reported a TPC result of $2.56-4.06 \mathrm{mg}$ GAE/g. The TPC of cocoa husk depends on the variety of cocoa plants (Amin and Chew, 2006; Nsor-Atindana et al. 2012). Other factors such as weather, soils, and environmental factors can also contribute to the chemical and physical content of the plants.

In the process of MAE, microwaves induce molecular motion in materials or solvents with dipoles. This caused the cocoa husks to heat, which in turn caused the plant cells to lose moisture through evaporation, swell, and eventually rupture, thereby releasing their active components. Time plays important role in ensuring that the extract still maintains its beneficial bioactive compound in an active state. In this study, different time treatments gave different yields of TPC. The best treatment was $10 \mathrm{~min}$, since it produced the highest TPC levels. This indicated that a longer extraction duration allowed dried cocoa husks to release more of their active compounds.

Recognition of the health potential of cocoa is a recent development, and much attention is now focused on the possible health benefits of cocoa. Cocoa contains bioactive compounds including catechin, which has many benefits. Catechin helps to protect against the development of coronary heart and cardiovascular diseases, delays oxidation of LDL cholesterol, improves endothelial function, lowers blood pressure, and improves platelet function (Dreosti, 2000; Miller et al. 2006). Several studies have confirmed that cocoa is a source of phenolic compounds (Bruna et al., 2009; Amin and Chew, 2006; Nsor-Atindana et al., 2012; Quiroz-Reyes et al., 2013).
Table 1. Total phenolic content (TPC) and total catechin content (TCC) of cocoa husks treated by microwave-assisted extraction (MAE)

\begin{tabular}{lcc}
\hline Extraction duration & $\begin{array}{c}\text { TPC } \\
(\mathbf{m g ~ G A E} / \mathbf{m L})\end{array}$ & $\begin{array}{c}\text { TCC } \\
(\boldsymbol{\mu g} / \mathbf{m L})\end{array}$ \\
\hline & & \\
A (4 min $)$ & $6.71^{\mathrm{a}} \pm 0.77$ & $47.80^{\mathrm{a}} \pm 0.08$ \\
B (6 min) & $7.18^{\mathrm{ab}} \pm 1.55$ & $48.83^{\mathrm{b}} \pm 0.16$ \\
C (8 min $)$ & $8.35^{\mathrm{bc}} \pm 0.05$ & $49.47^{\mathrm{c}} \pm 0.33$ \\
D $(10 \mathrm{~min})$ & $8.65^{\mathrm{c}} \pm 0.02$ & $51.03^{\mathrm{d}} \pm 0.23$ \\
\end{tabular}

Note: Different uppercase letters in the same column indicate a significant effect $(\mathrm{P}<0.05)$. Data are shown as mean \pm S.D.

\section{Total Catechin Content (TCC)}

The TCC of cocoa husk extract was analyzed by LCMS using catechin as a standard. The recovered TCC ranged from 47.80-51.03 $\mu \mathrm{g} / \mathrm{mL}$ (Table 1). Similar to TPC, significant effects $(\mathrm{P}<0.01)$ of extraction duration were observed on the total catechin content. A longer extraction duration increased the TPC recovered in the cocoa husk extract. The $10 \mathrm{~min}$ treatment gave optimal TCC.

The utilization of catechins in foods is an alternative way to supplement catechin consumption. Catechins have recently been isolated from cocoa, and several methods have been introduced for catechin analysis in cocoa husk extracts. However, LCMS was used in this study because it provides both quantitative and qualitative data regarding catechin content. TCC in this study was higher than the TCC reported in other studies. For example, Cruz et al. (2015) found a TCC without fermentation of 1.48-2.46 $\mathrm{mg} / \mathrm{g}$, which is more than $50 \%$ lower than the results obtained by the 4 min MAE in the present study; while the 10 min MAE produced the highest quantity of catechin. This result agrees with previous studies (Pervauzunalic et al. 2006) and may indicate that longer extraction times produce higher quantities of TCC. In a previous study, an increase in extraction temperature increased the phenolic and flavonoid contents of green and black tea extracts (Astill et al. 2001; Khokhar and Magnusdottir, 2002; Ziaedini et al. 2010; Rahayu et al. 2015). However, some methods can cause a loss of catechin due to degradation during long extraction times and high temperatures (Liu et al. 2005).

The MAE process produced higher TCC than other extraction methods. For example, the maceration and ultrasound-assisted extraction (UAE) process used by Quiroz-Reyes et al. (2013) yielded a TCC of only $0.28 \mu \mathrm{g} / \mathrm{mL}$ and $0.32 \mu \mathrm{g} / \mathrm{mL}$. According to Chemat et al. (2011), MAE is newly recognized as an innovative green technique that increases the extraction efficiency, making extractions faster and more effective. As noted, the results of extraction can be influenced by the cocoa variety and extraction process, as well as the choice of solvent, temperature, and extraction duration. In this study, the best treatment was $10 \mathrm{~min}$ since it yielded the highest TCC. 


\section{Liquid Chromatography-Mass Spectrometry (LC-MS)}

The mass spectrum of the catechin standard is presented in Figure 1. The peak of the protonated ion $[\mathrm{M}+\mathrm{H}]^{+}$ occurred at 291 . The $\mathrm{m} / \mathrm{z}$ signal at 291 would be a typical fragment ion detected in the mass spectrum of catechin. Figure 1 also shows that a peak at 291 for the protonated ion $[\mathrm{M}+\mathrm{H}]^{+}$in extracts $\mathrm{A}, \mathrm{B}, \mathrm{C}$, and $\mathrm{D}$, indicating that all extracts, regardless of extraction duration, contained catechin. The longer extraction duration resulted in a greater height of the peak. According to Calderon et al. (2009), their results for catechin analysis using LCMS gave a peak value of $\mathrm{m} / \mathrm{z} 289$.

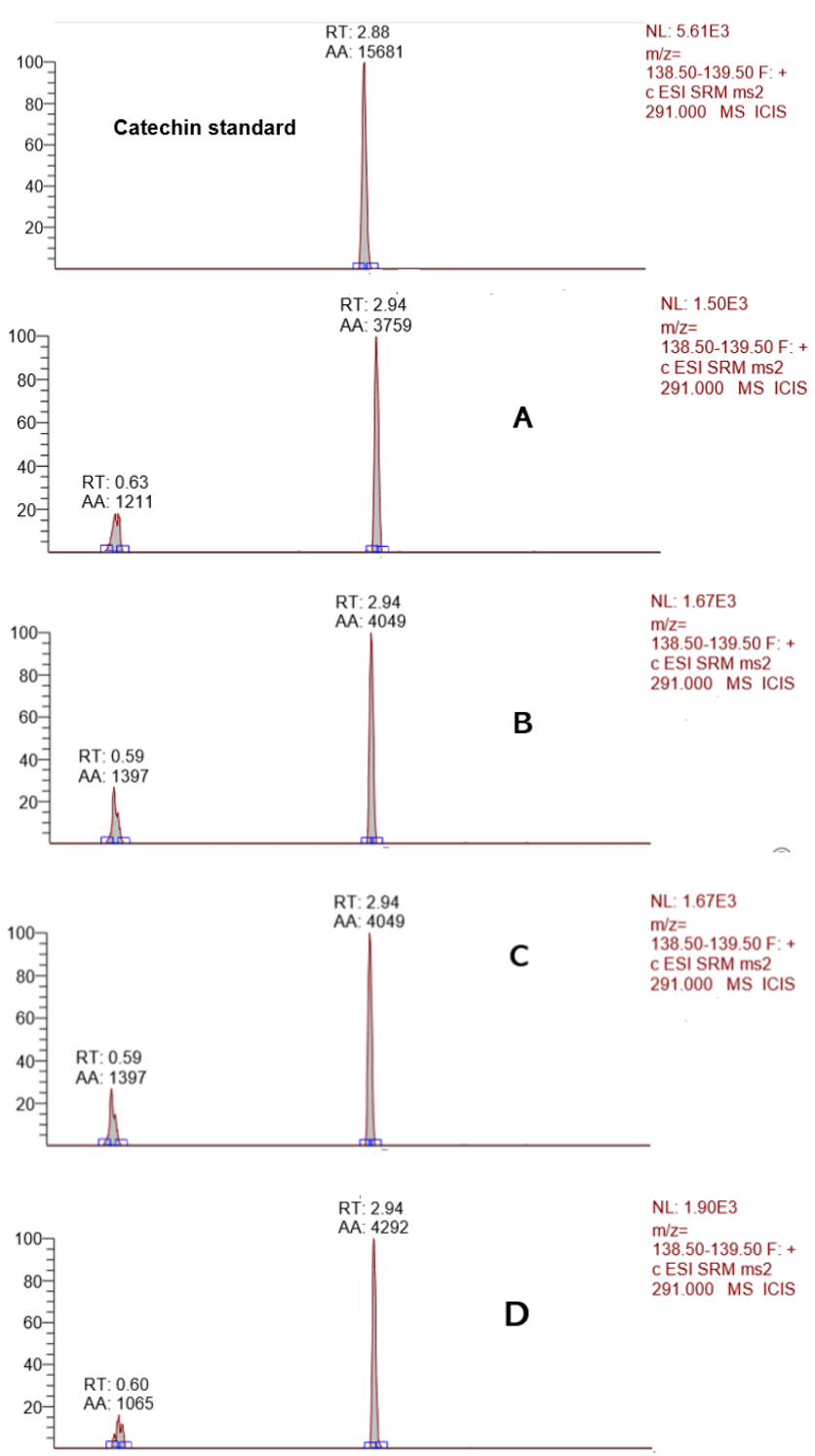

Figure 1. Chromatograms of cocoa husk extract. A: extract obtained by microwave-assisted extraction (MAE) for 4 min; B: extract obtained by MAE for 6 min; C: extract obtained by MAE for $8 \mathrm{~min}$; D: extract obtained by MAE for $10 \mathrm{~min}$
The catechin peaks in cocoa husks were identified by comparing the obtained mass spectra to standard and literature data. The retention times were 2.94 , whereas the standard RT was 2.88. Other previous published data showed that the RT for catechin from cocoa beans is 3.68 (Ortega et al. 2010). Therefore, separation and identification of catechin in cocoa husks by LC-MS/MS were identified successfully. The differences in the data may reflect differences in the starting material, since the earlier study used cocoa beans from Ghana (Ortega et al. 2010).

\section{Chemical structure - Fourier Transform Infrared Spectroscopy (FTIR)}

The peaks in the FTIR spectra at $3300-3500 \mathrm{~cm}^{-1}$ indicated $\mathrm{N}-\mathrm{H}$ amine/amide groups, and peaks at 3200$3600 \mathrm{~cm}^{-1}$ indicated $\mathrm{O}-\mathrm{H}$ alcohol hydrogen bonding/phenol. Peaks at 2850-2970 $\mathrm{cm}^{-1}$ and 1340-1470 $\mathrm{cm}^{-1}$ indicated C-H alkane groups. Peaks at $2500-2700 \mathrm{~cm}^{-1}$ indicated hydrogen bonding. Peaks at 1690-1760 $\mathrm{cm}^{-1}$ indicated C-O aldehyde/ketone/carboxylic acid/ester groups. Peaks at $1300-1370 \mathrm{~cm}^{-1}$ indicated $\mathrm{NO}_{2}$. Peaks at $1180-1360 \mathrm{~cm}^{-1}$ indicated C-N Amine/amide groups. Peaks at $1050-1300 \mathrm{~cm}^{-1}$ indicated $\mathrm{C}-\mathrm{O}$ alcohol/ether/carboxylic acid /ester groups. Peaks at $690-900 \mathrm{~cm}^{-1}$ indicated $\mathrm{C}-\mathrm{H}$ aromatic rings. Peaks at $675-995 \mathrm{~cm}^{-1}$ indicated $\mathrm{C}-\mathrm{H}$ alkene groups (Figure 2, Table 2).

The IR spectra of catechin extract using microwaveassisted extraction (MAE) for 4, 6, and 8 min were similar. However, the $10 \mathrm{~min}$ treatment produced different peaks, especially at $2500-2700 \mathrm{~cm}^{-1}$, indicating the presence of O$\mathrm{H}$ carboxylic acid groups. All the extracts contained phenolic compounds, as shown by the peaks at 690-900 $\mathrm{cm}^{-1}$. The peaks at $3200-3600 \mathrm{~cm}^{-1}$ agreed with the findings of Senthilkumar et al. (2017), who maintained that phenolics have peaks at $3270-3320 \mathrm{~cm}^{-1}$ and catechin has peaked at $1629-1663 \mathrm{~cm}^{-1}$. Treatment $\mathrm{D}(10 \mathrm{~min})$ gave rise to more peaks, especially for phenolic compounds and catechins, probably because this treatment allows a greater release of active compounds because of the longer extraction time (Figure 2, Table 2)..

This study showed that different durations of extraction by MAE produced different qualities of cocoa husk extracts. MAE for $10 \mathrm{~min}$ was the best treatment for cocoa husk extraction, as it produced higher quantities of TPC and TCC, at $8.65 \mathrm{mg} / \mathrm{mL}$ and $51.03 \mu \mathrm{g} / \mathrm{mL}$, respectively, than the other MAE durations. The results of LCMS and FTIR for all treatments indicated the presence of catechin compounds, although some treatments produced different spectra.

\section{ACKNOWLEDGEMENTS}

The authors appreciate the assistance of Dr. Alan McGee from Professional and Continuing Education (PACE), Massey University, for English proofreading. 


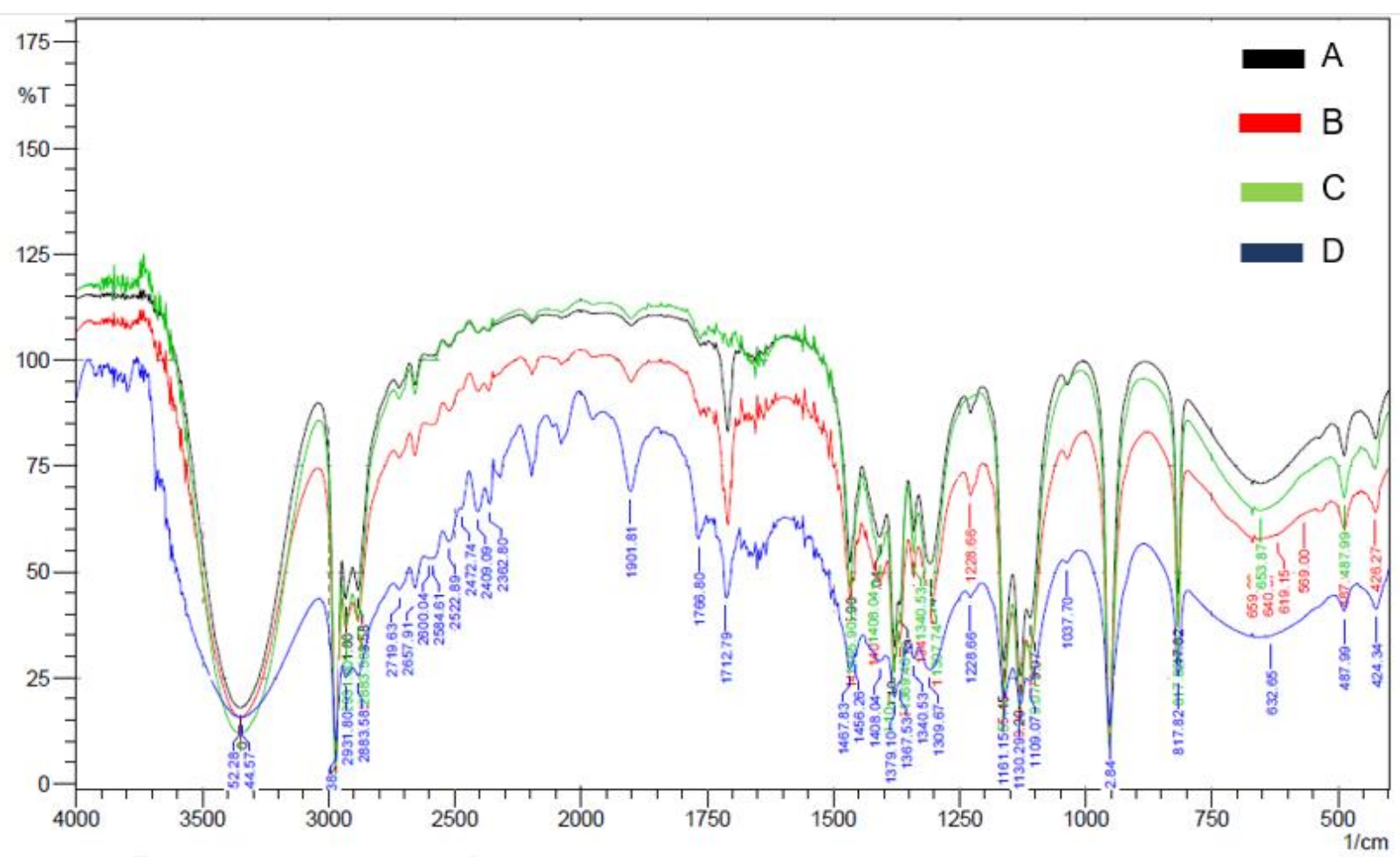

Figure 2. Functional groups of cocoa husk extract. A: extract obtained by microwave-assisted extraction (MAE) for 4 min; B: extract obtained by MAE for $6 \mathrm{~min}$; C: extract obtained by MAE for $8 \mathrm{~min}$; D: extract obtained by MAE for 10 min. For an explanation of the various symbols, see Table 2 .

Table 2. Functional groups of cocoa husk extract

\begin{tabular}{|c|c|c|c|c|c|}
\hline \multicolumn{4}{|c|}{ Extraction time for catechin using microwave-assisted extraction (MAE) } & \multirow{2}{*}{ Group } & \multirow{2}{*}{ Chemical structure } \\
\hline A 4 min & B 6 min & C 8 min & D 10 min & & \\
\hline \multirow{5}{*}{1109.1} & & & 1037.7 & C-O stretch & Alcohol, ester, carboxylic acids \\
\hline & & & & C-N stretch & Aliphatic amines \\
\hline & & & & C-OH stretch & Secondary alcohol \\
\hline & 1109.07 & 1109.07 & 1109.07 & C-O stretch & Alcohol, ester, carboxylic acids \\
\hline & 1228.66 & & 1228.66 & C-N stretch & Aliphatic amines \\
\hline \multirow{3}{*}{1465.9} & 1465.9 & 1465.9 & 1456.26 & C-C stretch (in ring) & Aromatic \\
\hline & & & 1712.79 & $\mathrm{C}=\mathrm{O}$ stretch & Polyphenols, catechin \\
\hline & & & 1766.8 & $\mathrm{C}=\mathrm{C}$ stretch & Aromatic \\
\hline 2883.6 & 2883.58 & 2883.58 & 2883.58 & C-H stretch & Alkanes \\
\hline 2931.8 & 2931.8 & 2931.8 & 2931.8 & C-H stretch & Alkanes \\
\hline 2970.4 & 2970.38 & 2970.38 & 2970.38 & O-H stretch & Carboxylic acid \\
\hline 3346.5 & 3346.5 & 3346.5 & 3344.57 & O-H. H-Bonded & Phenols, alcohol \\
\hline
\end{tabular}

\section{REFERENCES}

Amin I, Chew LY. 2006. Antioxidative effects of extracts of cocoa shell, roselle seeds and a combination of both extracts on the susceptibility of cooked beef to lipid oxidation. J Food Technol 4: 10-15.

Astill C, Birch M, Dacombe C, Humphrey P, Martin P. 2001. Factors affecting the caffeine and polyphenol contents of black and green tea infusions. J Agric Food Chem 49: 5340-5347. DOI: 10.1021/jf010759+.

Aswanida NN. 2015. A review on the extraction methods use in medicinal plants, principle, strength and limitation. Med Aromat Plants 4 (3): 16.
Beretta G, Furlanetto S, Regazzoni L, Zarrella M, Facino RM. 2008. Quenching of $\alpha, \beta$-unsaturated aldehydes by green tea polyphenols: HPLC-ESI-MS/MS studies. J Pharmaceut Biomed Anal 48: 606-611.

Biesaga M, Pyrzynska K. 2013. Stability of bioactive polyphenols from honey during different extraction methods. Food Chem 136: 46-54.

Bonvehi JS, Jorda RE. 1998. Constituents of cocoa husks. Z Naturforsch 53: 785-792.

Bruna C, Eichholz I, Rohn S, Kroh LW, Huyskens-Keil S. 2009. Bioactive compounds and antioxidant activity of cocoa hulls (Theobroma cacao L.) from different origins. J Appl Bot Food Qual 83: 9-13.

Calderon AI, Wright BJ, Hurst WJ., van Breemen RB. 2009. Screening antioxidants using LC-MS: Case study with cocoa. J Agric Food Chem 57: 5693-5699. DOI: 10.1021/jf9014203 
Chemat F, Zill-e-Huma, Khan MK. 2011. Applications of ultrasound in food technology: Processing, preservation and extraction. Ultrason Sonochem 18: 813-835. DOI: 10.1016/j.ultsonch.2010.11.023

Chen YM, Wang MK, Huang PM. 2006. Catechin transformation as influenced by aluminum. J Agric Food Chem 54: 212-218.

Clifford MN, Stoupi S, Kuhnert N. 2007. Profiling and characterization by LC-MS $\mathrm{n}$ of the galloylquinic acids of green tea, tara tannin, and tannic acid. J Agric Food Chem 55: 2797-2807.

Cruz JFM, Leite PB, Soares SE, Bispo E da S. 2015. Bioactive compounds in different cocoa (Theobroma cacao L) cultivars during fermentation. Food Sci Technol (Campinas) 35(2): 279-284. DOI: 10.1590/1678-457x.6541

Delazar A, Nahar L, Hamadeyazdan S, Sarker SD. 2012. Microwaveassisted extraction in natural product isolation. Methods Mol Biology864: 89-115.

Del Rio D, Stewart AJ, Mullen W, Burns J, Lean ME, Brighenti F, Crozier A. 2004. HPLC-MSn analysis of phenolic compounds and purine alkaloids in green and black tea. J Agric Food Chem 52: $2807-$ 2815.

Dreosti E. 2000 Antioxidant polyphenols in tea, cocoa, and wine Nutrition 16: 692-694.

Hernández-Hernández C, Viera-Alcaide I, Sillero AMM, FernándezBolaños J, Rodríguez-Gutiérrez G. 2018. Bioactive compounds in Mexican genotypes of cocoa cotyledon and husk. Food Chem, 240, 831-839.

Hernández-Jiménez A, Kennedy JA, Bautista-Ortín AB, Gómez-Plaza E. 2012. Effect of ethanol on grape seed proanthocyanidin extraction. Am J Enol Vitic 63: 57-61.

Jain T, Jain V, Pandey R, Vyas A, Shukla SS. 2009. microwave-assisted extraction for phytoconstituents - An overview. J Res Chem 1: 19-25.

Khokhar S, Magnusdottir SG. 2002. Total phenol, catechin, and caffeine contents of teas commonly consumed in the United Kingdom. J Agric Food Chem 50: 565-570. DOI: 10.1021/jf0101531.

Kim HS, Quon MJ, Kim JA. 2014. New insights into the mechanisms of polyphenols beyond antioxidant properties; lessons from the green tea polyphenol, epigallocatechin 3-gallate. Redox Biol 2: 187-195

Liu C-T, Wu C-Y, Weng Y-M, Tseng C-Y. 2005. Ultrasound-assisted extraction methodology as a tool to improve the antioxidant properties of herbal drug Xiaochia-hu-tang. J Ethnopharmacol 99: 293-300. DOI: 10.1016/j.jep.2005.02.018

Maung PP, He Q, Chamba MVM. 2012. Comparison of polypheno content between laboratory-processed Laphet and China and
Myanmar tea (Camellia sinensis) products. J Food Sci Pakistan 22: 180-184.

Miller KB, Stuart DA, Smith NL, Lee CY, McHale NL, Flanagan JA, Ou B, Hurst WJ. 2006. Antioxidant activity and polyphenol and procyanidin contents of selected commercially available cocoacontaining and chocolate products in the United States. J Agric Food Chem 54: 4062-4068.

Nsor-Atindana J, Zhong F, Mothibe KJ, Bangoura ML, Lagnika C. 2012. Quantification of total polyphenolic content and antimicrobial activity of cocoa (Theobroma cacao L.) bean shells. Pak J Nutr 11: 574-579.

Ortega N, Romero MP, Macia A, Reguant J, Angles N, Morello JR, Motilva MJ. 2009. Comparative study of ULPC-MS/MS and HPLCMS/MS to determine procyanidins and alkaloids in cocoa samples. $\mathbf{J}$ Food Compos Anal 23: 298-305.

Perva-Uzunalic A, Škerget M, Željko K, Weinreich B, Otto F, Grüner S. 2006. Extraction of active ingredients from green tea (Camellia sinensis) Extraction efficiency of major catechins and caffeine. Food Chem 96: 597-605.

Quiroz-Reyes CN, Aguilar-Mendez MA, Ramırez-Ortız ME, Ronquillo-De Jesus E. 2013. Comparative study of ultrasound and maceration techniques for the extraction of polyphenols from cocoa beans (Theobroma cacao L.). Rev Mex Ing Quím 12: 11-18.

Rahayu PP, Purwadi, Radiati, LE, Manab A. 2015. Physicochemical properties of whey protein and gelatine biopolymer using tea leaf extract as crosslink materials. Curr Res Nutr Food Sci 3: 224-236.

Redgwell R, Trovato V, Merinat S, Curti D, Hediger S, Manez A. 2003. Dietary fibre in cocoa shell: Characterisation of component polysaccharides. Food Chem 81: 103-112.

Senthilkumar SR, Sivakumar T, Arulmozhi KT, Mythili N. 2017. FT-IR analysis and correlation studies on the antioxidant activity, total phenolics and total flavonoids of Indian commercial teas (Camellia sinensis L.) - A novel approach. Intl Res J Biol Sci 6: 1-7.

Spacil Z, Novakova L, Solich P. 2008. Analysis of phenolic compounds by high-performance liquid chromatography and ultra-performance liquid chromatography. Talanta 76: 189-199.

Statistic Indonesia. 2018. Indonesia Cocoa Statistic 2017. Statistic Indonesia, ISBN: 978-602-438-251-3.

Velayutham P, Babu A, Liu D. 2008. Green tea catechins and cardiovascular health: an update. Curr Med Chem 15: 1840-1850.

Ziaedini A, Jafari A, Zakeri A. 2010. Extraction of antioxidants and caffeine from green tea (Camellia sinensis) leaves: kinetics and modelling. Food Sci Technol Intl 16: 505-510. DOI: $10.1177 / 1082013210367567$. 